\title{
The impact of different geometric assumption of mitral annulus on the assessment of mitral regurgitation volume by Doppler method
}

\author{
Wugang Wang, Zhibin Wang, Junfang Li, Kun Gong, Liang Zhao, Guozhang Tang and Xiuxiu Fu* (B)
}

\begin{abstract}
Background: Mitral regurgitation volume (MRvol) by quantitative pulsed Doppler (QPD) method previously recommended suffers from geometric assumption error because of circular geometric assumption of mitral annulus (MA). Therefore, the aim of this study was to evaluate the impact of different geometric assumption of MA on the assessment of MRvol by two-dimensional transthoracic echocardiographic QPD method.

Methods: This study included 88 patients with varying degrees of mitral regurgitation (MR). The MRvol was evaluated by QPD method using circular or ellipse geometric assumption of MA. MRvol derived from effective regurgitant orifice area by real time three-dimensional echocardiography (RT3DE) multiplied by MR velocity-time integral was used as reference method.

Results: Assumption of a circular geometry of MA, QPD-MAA4C and QPD-MAPLAX overestimated the MRvol by a mean difference of $10.4 \mathrm{ml}(P<0.0001)$ and $22.5 \mathrm{ml}(P<0.0001)$ compared with RT3DE. Assumption of an ellipse geometry of MA, there was no significant difference of MRvol (mean difference $=1.7 \mathrm{ml}, P=0.0844$ ) between the QPD-MAA4C+A2C and the RT3DE.

Conclusions: Assuming that the MA was circular geometry previously recommended, the MRvol by QPD-MA ${ }_{A 4 C}$ was overestimated compared with the reference method. However, assuming that the MA was ellipse geometry, the MRvol by the QPD-MA $A 4 C+$ A2C has no significant difference with the reference method.
\end{abstract}

Keywords: Mitral regurgitation volume, Quantitative pulsed Doppler, Real time three-dimensional echocardiography, Mitral annulus

\section{Introduction}

Mitral regurgitation (MR) is one of the most common heart-valve disorder, and its prevalence increases with age [1]. In the clinical decision-making process regarding mitral valvular lesions, accurate determination of the severity of the MR is of major importance [2, 3]. Echocardiography is the first method of non-invasive assessment of $\mathrm{MR}$, and mitral regurgitation volume (MRvol) is an important parameter to evaluate the severity of $M R$, which may be calculated by quantitative pulsed Doppler (QPD) method as previously recommended [4]. However, this

\footnotetext{
* Correspondence: fwanghao@sina.cn

Department of Echocardiography, The Affiliated Hospital of Qingdao University, No.16 Jiangsu Road, Qingdao 266003, China
}

method suffers from geometric limitations of twodimensional (2D) echocardiography. In the QPD method, important geometric errors are made in calculating the cross-sectional area (CSA) of the mitral annulus (MA) because of the circular geometric assumption (the CSA of MA was derived as $0.785 \mathrm{~d}^{2}$, where $\mathrm{d}$ was the diameter of the MA in the apical four-chamber view) [5]. Recently, a series of studies have confirmed that MRvol using effective regurgitant orifice area (EROA) (direct planimetry of EROA by real time three-dimensional color Doppler echocardiography) multiplied by the MR velocity-time integral $\left(\mathrm{VTI}_{\mathrm{MR}}\right)$ was highly accurate [6-8]. Therefore, the aim of this study was to evaluate the impact of different geometric assumption of MA on the assessment of MRvol by the traditional

(c) The Author(s). 2020 Open Access This article is distributed under the terms of the Creative Commons Attribution 4.0 International License (http://creativecommons.org/licenses/by/4.0/), which permits unrestricted use, distribution, and reproduction in any medium, provided you give appropriate credit to the original author(s) and the source, provide a link to the Creative Commons license, and indicate if changes were made. The Creative Commons Public Domain Dedication waiver (http://creativecommons.org/publicdomain/zero/1.0/) applies to the data made available in this article, unless otherwise stated. 
2D transthoracic echocardiographic (TTE) QPD method, by comparison with MRvol derived from EROA by real time three-dimensional color Doppler echocardiography.

\section{Methods}

\section{Study population}

This study included 88 patients ( 55 men, 33 women; mean age, $48.2 \pm 14.0$ years) with varying degrees of MR of different etiologies on color Doppler echocardiography between October 2011 and August 2017. The etiology of MR was ischemia in 32, idiopathic dilated cardiomyopathy in 26, mitral valve prolapse (MVP) in 30. MVP is diagnosed in the parasternal long-axis view as systolic displacement of the mitral leaflet into the left atrial of at least $2 \mathrm{~mm}$ from the MA plane [4]. Exclusion criteria included aortic regurgitation or stenosis, mitral stenosis, atrial fibrillation, frequent atrial or ventricular premature beats, congenital heart disease, hypertrophic cardiomyopathy, and poor general image quality. This study was approved by the institutional review board of The Affiliated Hospital of Qingdao University, and all patients underwent echocardiographic examination because of clinical indications and gave written informed consent.

\section{Echocardiographic examination}

2D and real time three-dimensional (3D) echocardiography (RT3DE) were performed using the iE33 ultrasound system (Philips Healthcare, Amsterdam, The Netherlands).
2D TTE: MRvol by QPD method using different geometric assumption of MA

2D TTE was performed with a S5-1 transducer, and patients were imaged in the left lateral decubitus position. The MA diameter was measured between the inner edges of the base of posterior and anterior leaflets in early to mid diastole at maximal mitral valve (MV) opening in the apical four-chamber (A4C), apical twochamber (A2C) and parasternal long-axis (PLAX) view $[5,9]$. The left ventricular outflow tract (LVOT) diameter was measured just below the aortic valve in early to mid systole in the PLAX view [5, 9]. The pulsed Doppler sample was carefully placed as parallel as possible to the blood flow in the A4C and apical five-chamber (A5C) views to obtain the Doppler spectral profiles of the MA and LVOT. The sample volume was positioned at the level of the MA and LVOT. The modal velocity profile on Doppler recordings was traced to obtain the velocitytime integral (VTI) [5, 9]. Data from three cardiac cycles was averaged.

MRvol by QPD was calculated as the difference between MA forward stroke volume $\left(\mathrm{SV}_{\mathrm{MA}}\right)$ and LVOT forward stroke volume $\left(\mathrm{SV}_{\mathrm{LVOT}}\right)$ (Fig. 1), that was $\mathrm{MRvol}=\mathrm{SV}_{\mathrm{MA}}-\mathrm{SV}_{\mathrm{LVOT}}$. $\mathrm{SV}_{\mathrm{LVOT}}$ was calculated as the VTI of LVOT $\left(\mathrm{VTI}_{\mathrm{LVOT}}\right)$ multiplied by the crosssectional area (CSA) of LVOT (CSA $\left.\mathrm{LVOT}_{\mathrm{L}}\right)$. The LVOT is circular and the $\mathrm{CSA}_{\mathrm{LVOT}}$ is derived as: $\pi \mathrm{d}^{2} / 4$, that is $0.785 \mathrm{~d}^{2}$. Thus, $\mathrm{SV}_{\mathrm{LVOT}}=0.785 \mathrm{~d}^{2} \times \mathrm{VTI}_{\mathrm{LVOT}}$, where $\mathrm{d}$ is the diameter of the LVOT in the PLAX view [4].

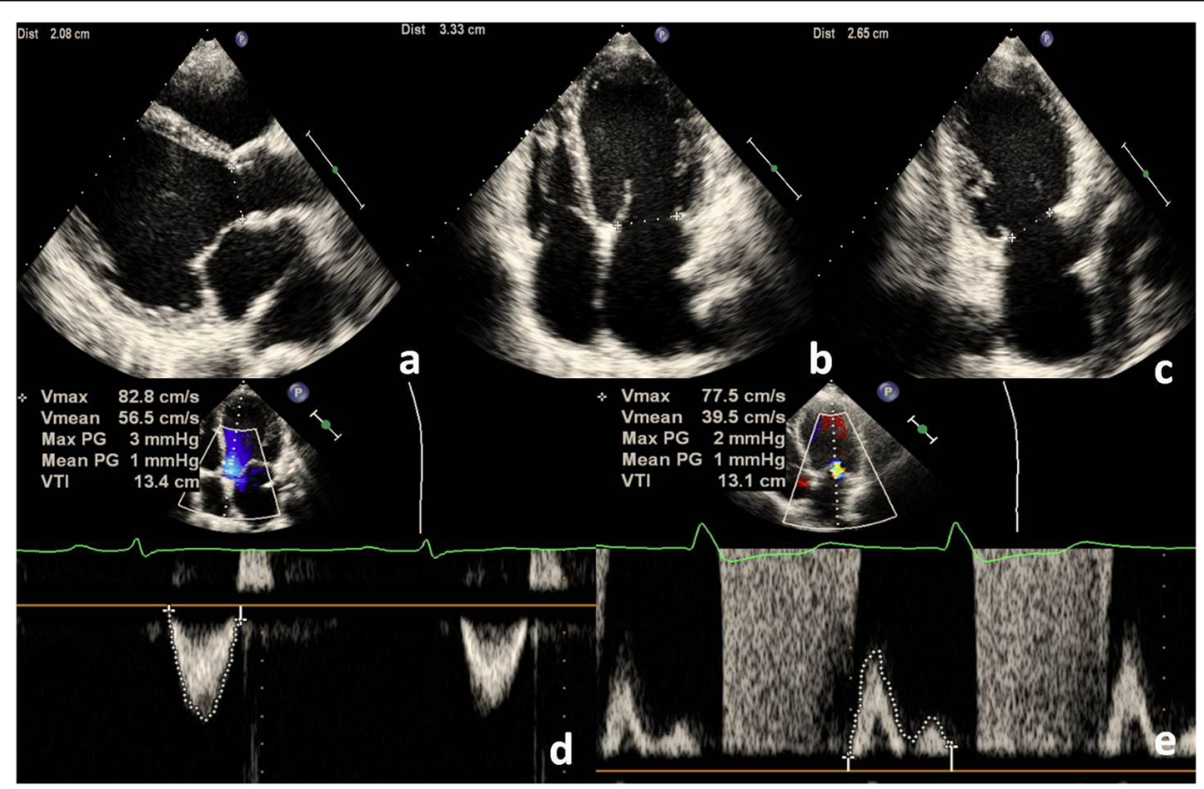

Fig. 1 QPD calculations of MRvol assuming that the MA is ellipse geometry. a The diameter of LVOT was measured in the PLAX view, and the CSA $_{\text {LVOT }}$ was derived as $0.785 \mathrm{~d}^{2}$. d LVOT pulsed Doppler was traced to obtain the VTI LVOT. ThuS, SV LVOT $=0.785 \mathrm{~d}^{2} \times \mathrm{VTI}_{\text {LVOT }}=0.785 \times 2.08^{2} \times$ $13.4=45.51 \mathrm{ml}$. $\mathbf{b}$ and $\mathbf{c}$ The diameter of MA was measured in the A4C and A2C view. The CSAMA was derived as $0.785 \times a \times b$. e MA inflow pulsed Doppler was traced to obtain the $\mathrm{VTI}_{\mathrm{MA}}$. Thus, $\mathrm{SV}_{\mathrm{MA}}=0.785 \times \mathrm{a} \times \mathrm{b} \times \mathrm{VTI} \mathrm{I}_{\mathrm{MA}}=0.785 \times 3.33 \times 2.65 \times 13.1=90.75 \mathrm{ml}$. In this example of $\mathrm{MR}$, MRVol $=S V_{M A}-S_{\text {LVOT }}=90.75-45.51=45.24 \mathrm{ml}$ 
$\mathrm{SV}_{\mathrm{MA}}$ was calculated as the VTI of MA $\left(\mathrm{VTI}_{\mathrm{MA}}\right)$ multiplied by the CSA of MA (CSA $\left.\mathrm{CA}_{\mathrm{MA}}\right)$. Assuming that the MA is circular geometry (Fig. 2), the $\mathrm{CSA}_{\mathrm{MA}}$ is derived as $0.785 \mathrm{~d}^{2}$. Thus, $\mathrm{SV}_{\mathrm{MA}}=0.785 \mathrm{~d}^{2} \times \mathrm{VTI}_{\mathrm{MA}}$, where $\mathrm{d}$ was the diameter of the MA in the PLAX, A4C or A2C view. Assuming that the MA is ellipse geometry (Fig. 1), the $\mathrm{CSA}_{\mathrm{MA}}$ is derived as $0.785 \times \mathrm{a} \times \mathrm{b}$. Thus, $\mathrm{SV}_{\mathrm{MA}}=0.785 \times \mathrm{a} \times \mathrm{b} \times \mathrm{VTI}_{\mathrm{MA}}$, where $\mathrm{a}$ is the diameter of the MA in $\mathrm{A} 4 \mathrm{C}$ and $\mathrm{b}$ in $\mathrm{A} 2 \mathrm{C}$ view, $\mathrm{a}$ in $\mathrm{A} 4 \mathrm{C}$ and $\mathrm{b}$ in PLAX view or a in A2C and $b$ in PLAX view $[4,10,11]$.

\section{Real-time 3D color Doppler echocardiograpy: MRvol by RT3DE}

3D color Doppler data were acquired immediately after the 2D TTE using the same system equipped with a fully sampled matrix-array X3-1 transducer from the apical view, combining 7 small real-time subvolumes into a larger pyramidal volume. Nyquist limits were set between 40 and $60 \mathrm{~cm} / \mathrm{sec}$ to avoid any overestimation or underestimation. Patients were asked to hold respiration during imaging acquisition.

Three-dimensional color Doppler data sets were analyzed offline using software (QLAB version 7.1). Using multiplanar reconstruction of the 3D color Doppler data sets, a cross-sectional plane through the vena contracta perpendicular to the jet direction was selected, and the cross-sectional plane was then moved along the jet direction as far as the smallest cross-sectional area $[7,10]$. The EROA was determined using manual planimetry of the color Doppler flow signal from an en face view, and the MRvol was calculated as EROA by RT3DE multiplied by the $\mathrm{VTI}_{\mathrm{MR}}$ (Fig. 3). An MRvol $>60 \mathrm{ml}$ was used to define severe MR [4].

\section{Statistical analysis}

Continuous data were presented as mean $\pm \mathrm{SD}$. Categorical data were presented as percentages or absolute numbers. One factorial analysis of variance was used to compare the MA diameters measured in different views and the $\mathrm{CSA}_{\mathrm{MA}}$ calculated using the different geometric assumption. Pearson's correlation analysis was performed to evaluate the relation between QPD and RT3DE measurements of MRvol. Bland-Altman analysis was performed to evaluate the differences in MRvol assessed with QPD and RT3DE. Differences were considered statistically significant at $P<0.05$. Statistical analysis was performed using MedCalc version 15.2 (MedCalc Software, Mariakerke, Belgium).

\section{Results}

Clinical and echocardiographic characteristics of the MR patients are listed in Table 1.

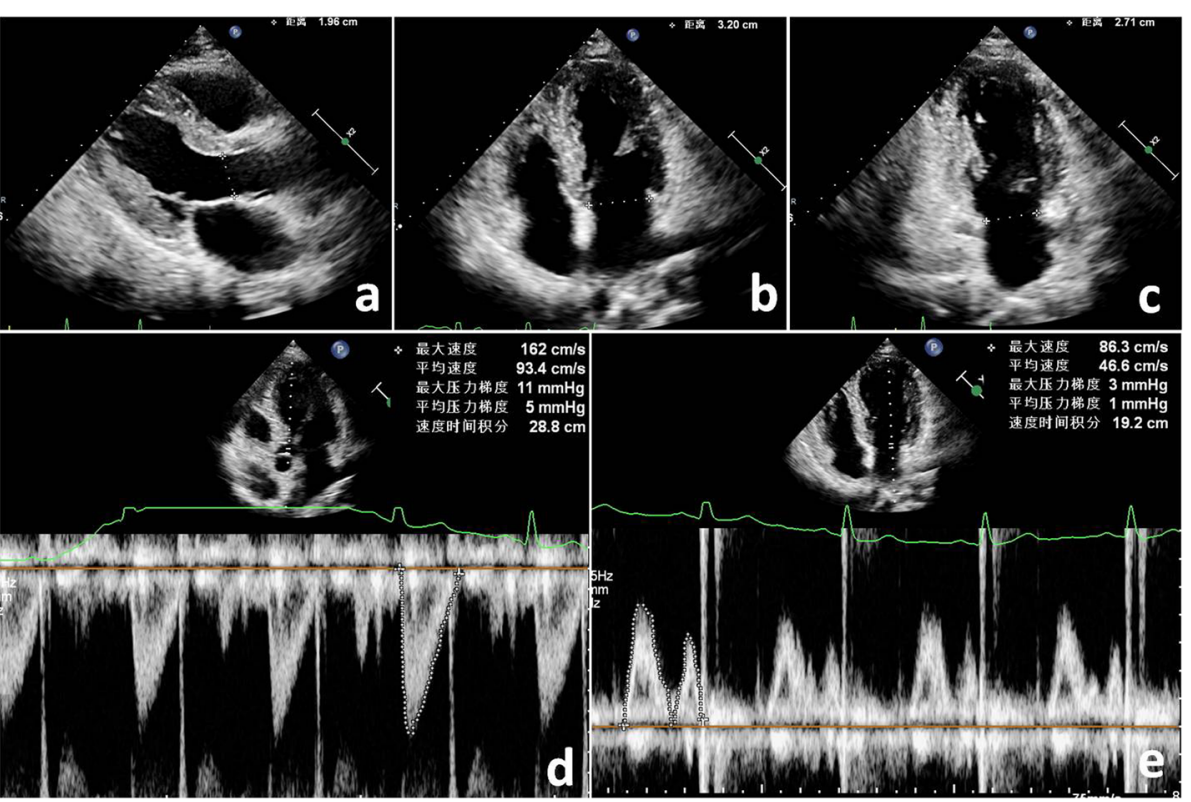

Fig. 2 QPD calculations of MRvol assuming that the MA is circular geometry. a The diameter of LVOT was measured in the PLAX view, and the $\mathrm{CSA}_{\text {LVOT }}$ was derived as $0.785 \mathrm{~d}^{2}$. $\mathbf{d}$ LVOT pulsed Doppler was traced to obtain the VTI LVOT. ThuS, SV LVOT $=0.785 \mathrm{~d}^{2} \times \mathrm{VTI}_{\mathrm{LVOT}}=0.785 \times 1.96^{2} \times$ $28.8=86.85 \mathrm{ml}$. $\mathbf{b}$ and $\mathbf{c}$ The diameter of MA was measured in the A4C and A2C view. The CSA $A_{A 4 C}$ was derived as $0.785 \times 3.2^{2}$, and CSA $A_{A 2 C}$ was derived as $0.785 \times 2.71^{2}$. e MA inflow pulsed Doppler was traced to obtain the $\mathrm{VTI}_{\mathrm{MA}}$. Thus, $\mathrm{SV}_{\mathrm{A} 4 \mathrm{C}}=0.785 \times 3.2^{2} \times 19.2=154.33 \mathrm{ml}$, and $\mathrm{SV}_{\mathrm{A} 2 \mathrm{C}}=$ $0.785 \times 2.71^{2} \times 19.2=110.69 \mathrm{ml}$. In this example of MR, MRvol by $Q P D-M A_{A 4 C}=S V_{A 4 C}-S V_{\text {LVOT }}=154.33-86.85=67.48 \mathrm{ml}$, and MRvol by $Q P D-M A_{A 2 C}=110.69-86.85=23.84 \mathrm{ml}$ 


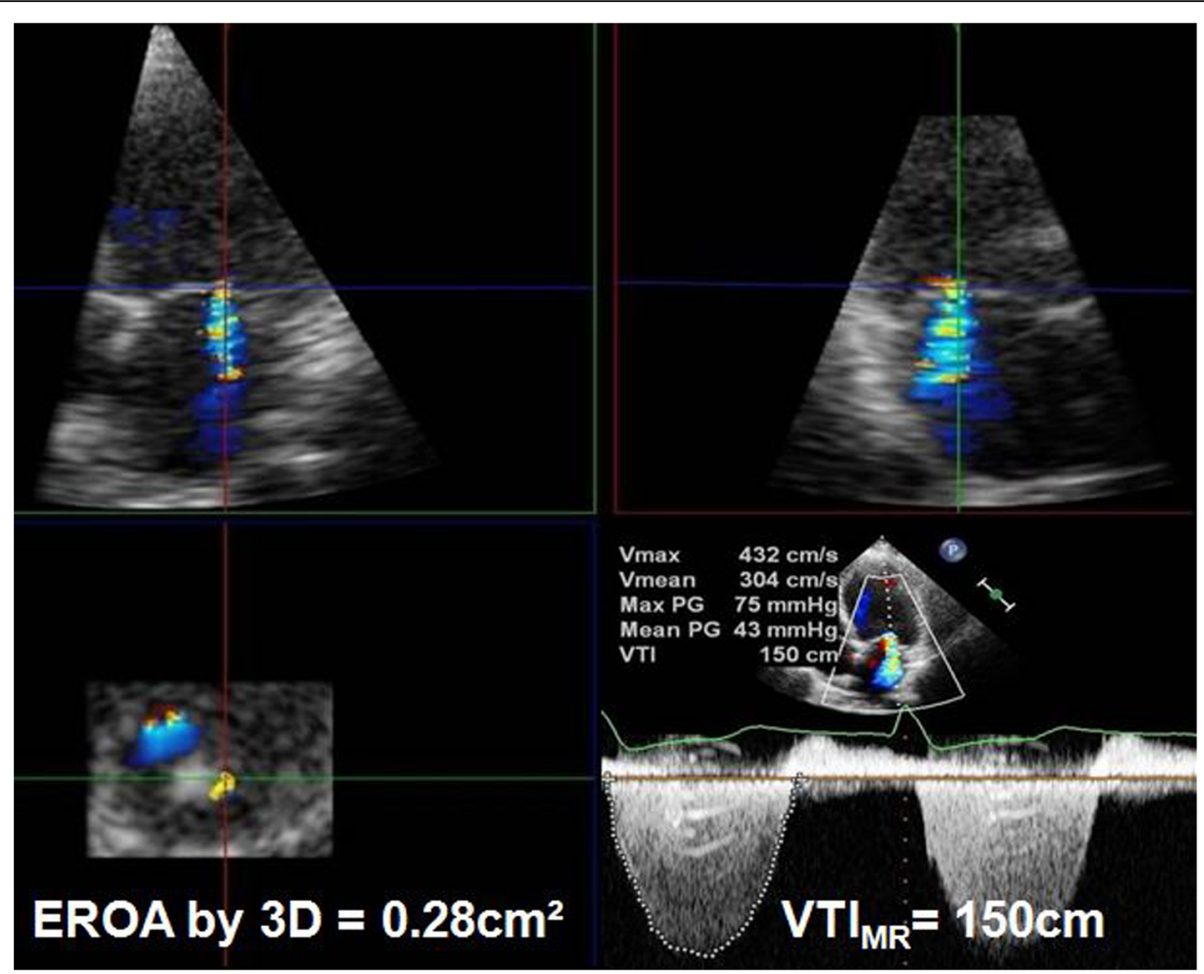

Fig. $3 \mathrm{MRvol}$ calculated as EROA by RT3DE multiplied by the $\mathrm{VTI}_{\mathrm{MR}}$. The 3D color Doppler data was manually cropped by the cross-sectional plane perpendicularly to the regurgitant jet direction up to the smallest cross-sectional area of the regurgitant jet. The EROA was determined using manual planimetry of the color Doppler flow signal from an en face view. Example of a MR patient: $E R O A=0.28 \mathrm{~cm}^{2}$,

$\mathrm{VTI}_{\mathrm{MR}}=150 \mathrm{~cm}, \mathrm{MRvol}=0.28 \times 150=42 \mathrm{~mL}$

Table 1 Patient characteristics $(n=88)$

\begin{tabular}{ll}
\hline Variable & Value \\
\hline Age (y) & $48.2 \pm 14.0$ \\
Men/women & $55 / 33$ \\
Heart rate (beats/min) & $74.8 \pm 13.8$ \\
Systolic BP (mm Hg) & $112.5 \pm 18.7$ \\
Diastolic BP (mm Hg) & $73.1 \pm 9.5$ \\
LVEDD (cm) & $5.9 \pm 1.1$ \\
LVESD (cm) & $4.5 \pm 1.5$ \\
LVEF (\%) & $53.1 \pm 18.5$ \\
LVOT diameter (mm) & $2.0 \pm 0.1$ \\
VTI LVOT (cm) & $17.3 \pm 5.0$ \\
VTI $\left.\right|_{\text {MA }}(\mathrm{cm})$ & $17.9 \pm 5.4$ \\
VTI & $131.1 \pm 29.9$ \\
EROA by RT3DE (cm ${ }^{2}$ ) & $0.33 \pm 0.14$ \\
\hline$B P$ Blood pressure, $L V E D D$ Left ventricular end-diastolic diameter, & LVESD Left \\
ventricular end-systolic diameter, LVEF Left ventricular ejection fraction, EROA \\
by RT3DE The EROA was measured by manual planimetry of the 3D color \\
Doppler signal; Data are expressed as mean \pm SD or as number
\end{tabular}

Comparison of MA diameter in different views and $\mathrm{CSA}_{\mathrm{MA}}$ based on different geometric assumption

As listed in Table 2, ANOVA showed significant differences among the 2D TTE diameters of the MA in three different views. The MA diameters in PLAX view were larger than the MA diameters in $\mathrm{A} 4 \mathrm{C}$ or $\mathrm{A} 2 \mathrm{C}$ view $\left(\mathrm{MA}_{\mathrm{PLAX}}\right.$ vs $\mathrm{MA}_{\mathrm{A} 4 \mathrm{C}}$ or $\mathrm{MA}_{\mathrm{A} 2 \mathrm{C}}$ : $3.0 \pm 0.4$ vs $2.9 \pm 0.4$ or $2.7 \pm 0.3, P<0.001)$. As for CSA of the MA, the CSA PLAX derived from circular geometric assumption was larger than $\mathrm{CSA}_{\mathrm{A} 4 \mathrm{C}}$ and $\mathrm{CSA}_{\mathrm{A} 2 \mathrm{C}}$ or $\mathrm{CSA}_{\mathrm{PLAX}+\mathrm{A} 4 \mathrm{C}}, \mathrm{CSA}_{\mathrm{PLAX}+}$

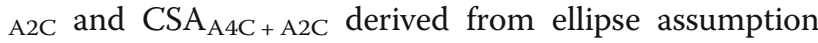
$(P<0.001$ for all).

\section{Assumption of a circular geometry of MA, MRvol by QPD} compared with reference method

Compared with MRvol by RT3DE, MRvol by QPD$\mathrm{MA}_{\mathrm{A} 4 \mathrm{C}}$ and QPD-MA $\mathrm{A}_{2 \mathrm{C}}$ showed good correlation $(r=$ $0.822, P<0.0001 ; r=0.805, P<0.0001)$, while MRvol by QPD-MA $A_{\text {PLAX }}$ demonstrated poor correlation $(r=0.574$, $P<0.0001)$. QPD-MA $A_{\text {LAX }}$ and QPD-MA $44 \mathrm{C}$ overestimated the MRvol by a mean difference of $22.5 \mathrm{ml}(P<$ $0.0001)$ and $10.4 \mathrm{ml}(P<0.0001)$ compared with RT3DE (Fig. 4). However, QPD-MA $\mathrm{A}_{\mathrm{A} 2 \mathrm{C}}$ underestimated the MRvol by a mean difference of $5.5 \mathrm{ml}(p=0.0002)$ compared with RT3DE (Fig. 5). 
Table 2 Results of ANOVA analysis for MA diameter and CSA

\begin{tabular}{|c|c|c|c|}
\hline \multirow[t]{2}{*}{ Variable } & \multirow[t]{2}{*}{ Value } & \multicolumn{2}{|c|}{ ANOVA analysis } \\
\hline & & $F$ & $P$ \\
\hline \multicolumn{4}{|c|}{ MA diameter (cm) } \\
\hline MA $A_{P L A X}$ & $3.0 \pm 0.4$ & 18.471 & $<0.001$ \\
\hline $\mathrm{MA}_{\mathrm{A} 4 \mathrm{C}}$ & $2.9 \pm 0.4$ & & \\
\hline$M A_{A 2 C}$ & $2.7 \pm 0.3$ & & \\
\hline \multicolumn{4}{|c|}{ Circular assumption $\left(\mathrm{cm}^{2}\right)$} \\
\hline CSAPLAX & $7.1 \pm 1.9$ & 9.992 & $<0.001$ \\
\hline $\mathrm{CSA}_{\mathrm{A} 4 \mathrm{C}}$ & $6.6 \pm 1.7$ & & \\
\hline $\mathrm{CSA}_{\mathrm{A} 2 \mathrm{C}}$ & $5.7 \pm 1.2$ & & \\
\hline \multicolumn{4}{|c|}{ Ellipse assumption $\left(\mathrm{cm}^{2}\right)$} \\
\hline$C S A_{P L A X}+A 4 C$ & $6.8 \pm 1.6$ & & \\
\hline CSAPLAX + AZC & $6.3 \pm 1.4$ & & \\
\hline $\mathrm{CSA}_{\mathrm{A} 4 \mathrm{C}}+\mathrm{A} 2 \mathrm{C}$ & $6.1 \pm 1.3$ & & \\
\hline
\end{tabular}

$M A_{P L A X}, M A_{A 4 C}$ and $M A_{A 2 C}$ diameter The MA diameter was measured in PLAX, $\mathrm{A} 4 \mathrm{C}$ and $\mathrm{A} 2 \mathrm{C}$ view, CSA $A_{\text {PLAX }}$ The CSA of MA was calculated from the MA diameter in PLAX view using circular geometric assumption $\left(C S A=0.785 \mathrm{~d}^{2}\right)$, $C_{C S A_{P L A X}+A 4 C}$ The CSA of MA was calculated from the MA diameter in PLAX and $A 4 C$ view using ellipse assumption $(C S A=0.785 \times a \times b)$

\section{Assumption of a ellipse geometry of MA, MRvol by QPD compared with reference method}

MRvol by QPD-MA PLAX + A4C and QPD-MA PLAX + A2C demonstrated good correlation compared with RT3DE $(r=0.789, \quad P<0.0001 ; \quad r=0.776, \quad P<0.0001)$. QPD-MA $P L A X+A 4 C$ and QPD-MA $P$ LAX + A2C overestimated the MRvol by a mean difference of $15.2 \mathrm{ml}(P<$ $0.0001)$ and $6.8 \mathrm{ml}(P=0.0002)$ when compared with

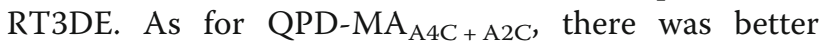
correlation compared with RT3DE $(r=0.905, \quad P<$ 0.0001 ), and the Bland-Altman analysis revealed no significant difference (mean difference $=1.7 \mathrm{ml}, P=$ 0.0844) (Fig. 6). The correlation and difference between MRvol measured by QPD and RT3DE is summarized in Table 3 .

\section{Categorizations of MR severity according to different methods}

On the basis of MRvol by RT3DE, 19 (21.6\%) patients had severe MR (MRvol > $60 \mathrm{ml})$. Assuming that the MA is circular geometry, $42(47.8 \%)$ patients had severe MR based on QPD-MA ${ }_{\text {PLAX }} 31$ (35.2\%) patients had severe MR based on QPD-MA $\mathrm{A}_{4 \mathrm{C}}$, and 12 (13.6\%) patients had severe $\mathrm{MR}$ based on $\mathrm{QPD}-\mathrm{MA}_{\mathrm{A} 2 \mathrm{C}}$. Assuming that the MA is ellipse geometry, 40 (45.4\%) patients had severe MR based on QPD-MAPLAX + A4C, 28 (31.8\%) patients had severe MR based on QPD-MA $A_{\text {LAX }+A 2 C}$, and 22 (25\%) patients had severe $\mathrm{MR}$ based on $\mathrm{QPD}-\mathrm{MA}_{\mathrm{A} 4 \mathrm{C}+}$ A2C.

Compared with MRvol by RT3DE, MR severity using QPD-MA $A_{\text {PLAX }}$, QPD-MA $44 \mathrm{C}$, QPD-MA 2 PLAX + A4C, and QPD-MA PLAX + A2C were overestimated in 23 (26.1\%) patients, in $12(13.6 \%)$ patients, in 21 (23.8\%) patients, and in $9(10.2 \%)$ patients, respectively, and MR severity using QPD-MA $\mathrm{A}_{\mathrm{A} 2 \mathrm{C}}$ was underestimated in 7 (10.2\%) patients. Although $\mathrm{MR}$ severity using $\mathrm{QPD}-\mathrm{MA}_{\mathrm{A} 4 \mathrm{C}+\mathrm{A} 2 \mathrm{C}}$ was overestimated in $3(3.4 \%)$ patients, Chi-squared revealed no significant difference $(P=0.724)$.

\section{Discussion}

The main finding of this study was that compared with the MRvol using EROA by RT3DE multiplied by the $\mathrm{TVI}_{\mathrm{MR}}$, the MRvol was overestimated significantly by the 2D TTE QPD $_{\mathrm{A} 4 \mathrm{C}}$ method previously recommended $[2,4]$. The overestimates were caused by the circular geometric assumption of the MA, which led to the CSA $\mathrm{A} 4 \mathrm{C}$ and corresponding $\mathrm{SV}_{\mathrm{MA}}$ being overestimated. In our study, assumption of an ellipse geometry of MA, MRvol calculated by $\mathrm{QPD}_{\mathrm{A} 4 \mathrm{C}+\mathrm{A} 2 \mathrm{C}}$ showed better correlation $(r=0.905, P<0.0001)$ and had no significant difference (mean difference $=1.7 \mathrm{ml}, P=0.0844$ ) with MRvol by RT3DE.

MRvol by QPD is simple in theory. Stroke volume (SV) at aortic valve or MV is derived as the product of
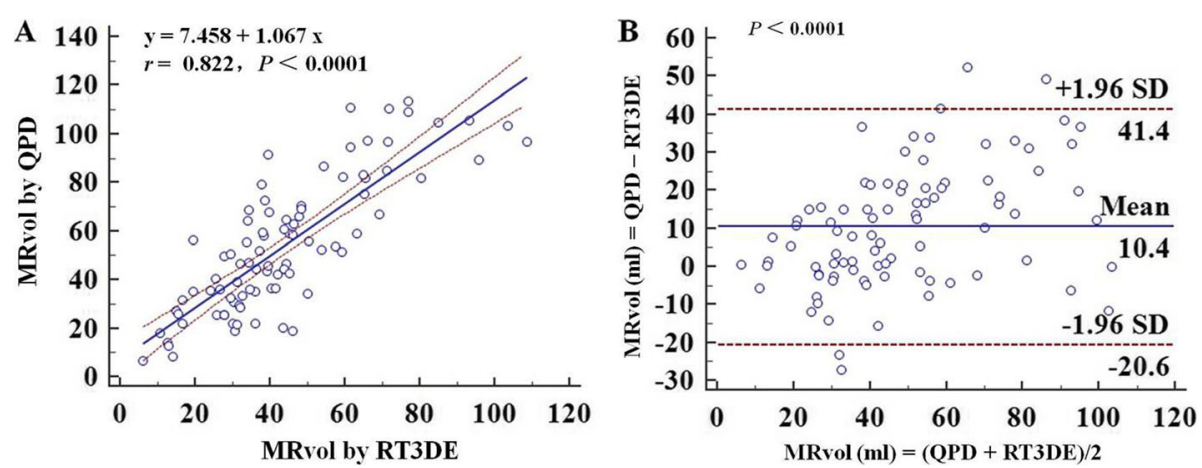

Fig. 4 Assumption of a circular geometry of MA, linear regression plot and Bland-Altman plot showing correlations (a) and agreement (b) between MRvol by QPD-MAA4C and RT3DE 

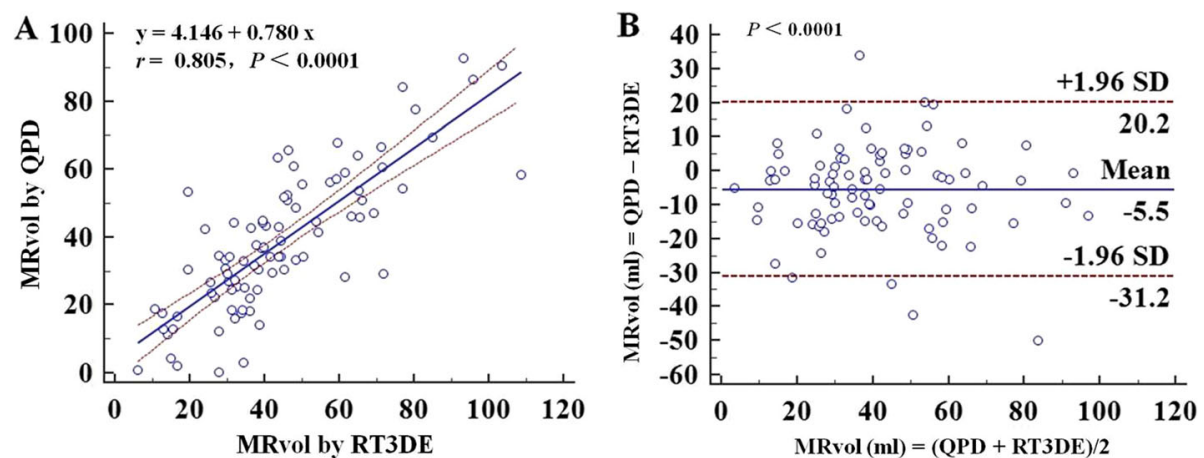

Fig. 5 Assumption of a circular geometry of MA, linear regression plot and Bland-Altman plot showing correlations (a) and agreement (b) between MRvol by QPD-MA $A_{A 2 C}$ and RT3DE

CSA and VTI of flow at the LVOT or MA. In the absence of MR, SV determinations at LVOT and MA are equal. In the presence of MR, without any intracardiac shunt, the flow through MA is larger than through the LVOT. The difference between the two represents the MRvol [12]. For MRvol by QPD method, it is very important to accurately evaluate the $\mathrm{CSA}_{\mathrm{MA}}$ and $\mathrm{CSA}_{\mathrm{LVOT}}$. The calculation method of $\mathrm{CSA}_{\mathrm{LVOT}}$ is nearly consistent $\left(\mathrm{CSA}_{\mathrm{LVOT}}=\pi \mathrm{d}^{2} / 4\right.$, where $\mathrm{d}$ was the diameter of the LVOT in the PLAX view) $[2,4$, 9]. However, the calculation method of $\mathrm{CSA}_{\mathrm{MA}}$ is controversial [5]. The MA diameter was measured in the A4C view and the CSA $\mathrm{MA}_{\mathrm{MA}}$ werived as $0.785 \mathrm{~d}^{2}$ (where $\mathrm{d}$ is the MA diameter in $\mathrm{A} 4 \mathrm{C}$ ) assuming that the MA is circular geometry as previously recommended $[4,9]$. However, previous studies have been demonstrated that the MA has a saddle-shaped contour [13] and the CSA of the MA are oval, with the major and minor diameter [5, 14, 15]. Ren et al. [5] studied geometric errors of the MA by RT3DE. They found that the MA geometry was oval in the 3D en face views with a significant difference between the major and minor diameters. The $2 \mathrm{D}$ diameters of the $\mathrm{MA}_{\mathrm{A} 4 \mathrm{C}}$ was significantly different from both the major and minor diameters. Assuming that the MA was circular geometry, the CSA of the $\mathrm{MA}_{\mathrm{A} 4 \mathrm{C}}$ by $2 \mathrm{D}$ TTE overestimated the CSA compared with RT3DE [5]. In our study, the QPD-MAPLAX and QPD-MA ${ }_{\mathrm{A} 4 \mathrm{C}}$ overestimated the MRvol (mean difference $=22.5 \mathrm{ml}, P<0.0001$; mean difference $=10.4 \mathrm{ml}, P<$ $0.0001)$ and QPD-MA $\mathrm{A}_{2 \mathrm{C}}$ underestimated the MRvol (mean difference $=5.5 \mathrm{ml}, P=0.0002$ ) compared with the MRvol by RT3DE. A possible reason is that the 2D $\mathrm{MA}_{\text {PLAX }}$ and $\mathrm{MA}_{\mathrm{A} 4 \mathrm{C}}$ diameters may approach the $3 \mathrm{D}$ major diameters, and the $\mathrm{MA}_{\mathrm{A} 2 \mathrm{C}}$ may be close to the $3 \mathrm{D}$ minor diameters as previous findings $[5,16]$. Based on the assumption of circular geometry, the monoplanar measurements of MA diameter and false geometric assumption are crucial factors of error using the 2D TTE QPD method. This error is important because the MA diameter is squared to derive the $\mathrm{CSA}_{\mathrm{MA}}$ in the geometric circular assumption formula, which result in an overestimation of the CSA $_{P L A X}$ and CSA $_{A 4 C}$ and an underestimation of the $\mathrm{CSA}_{\mathrm{A} 2 \mathrm{C}}$. Because of these, the corresponding $\mathrm{SV}_{\mathrm{MA}}$ calculated by CSA $\mathrm{PLAX}_{\mathrm{X}}$ or $\mathrm{CSA}_{\mathrm{A} 4 \mathrm{C}}$ is overestimated, and the corresponding $\mathrm{SV}_{\mathrm{MA}}$ calculated by $\mathrm{CSA}_{\mathrm{A} 2 \mathrm{C}}$ is underestimated. Consequently, the QPD-MA $\mathrm{PLAX}_{\text {and }}$ QPD-MA $\mathrm{A}_{4 \mathrm{C}}$ overestimated the MRvol and QPD-MA $\mathrm{A}_{\mathrm{A} C}$ underestimated the MRvol, which may cause over- or underestimation of MR severity. In our present study, compared with MRvol by RT3DE, MR severity using QPD-MA PLAX $_{\text {and }}$ QPD-
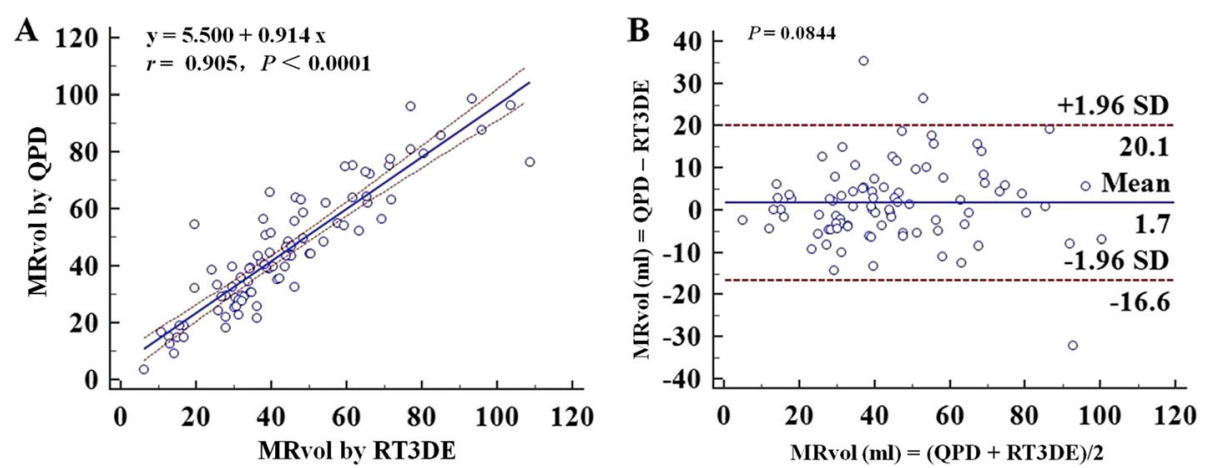

Fig. 6 Assumption of an ellipse geometry of MA, linear regression plot and Bland-Altman plot showing correlations (a) and agreement (b) between MRvol by QPD-MA $A 4 C+$ A2C and RT3DE 
Table 3 Results of Pearson's correlation and Bland-Altman analysis for MRvol by QPD and reference methods

\begin{tabular}{|c|c|c|c|c|c|c|}
\hline \multirow[t]{2}{*}{ Method } & \multirow[t]{2}{*}{ MRvol (ml) } & \multicolumn{2}{|c|}{ Pearson's correlation analysis } & \multicolumn{3}{|l|}{ Bland-Altman analysis } \\
\hline & & $r$ & $p$ & Mean difference (ml) & $95 \%$ limits of agreement $(\mathrm{ml})$ & $p$ \\
\hline \multicolumn{7}{|l|}{ Circular assumption } \\
\hline QPD-MAPLAX & $66.4 \pm 41.1$ & 0.574 & $<0.0001$ & 22.5 & $-43.6 \sim 88.6$ & $<0.0001$ \\
\hline QPD-MA $A_{A 4 C}$ & $54.3 \pm 27.6$ & 0.822 & $<0.0001$ & 10.4 & $-20.6 \sim 41.4$ & $<0.0001$ \\
\hline QPD-MA $A_{A 2 C}$ & $38.4 \pm 20.6$ & 0.805 & $<0.0001$ & -5.5 & $-31.7 \sim 20.2$ & 0.0002 \\
\hline RT3DE & $43.9 \pm 21.3$ & & & & & \\
\hline \multicolumn{7}{|l|}{ Ellipse assumption } \\
\hline QPD-MAPLAX + A4C & $59.1 \pm 29.5$ & 0.789 & $<0.0001$ & 15.2 & $-20.5 \sim 51.0$ & $<0.0001$ \\
\hline QPD-MAPLAX + AZC & $50.6 \pm 25.6$ & 0.776 & $<0.0001$ & 6.8 & $-24.9 \sim 38.5$ & 0.0002 \\
\hline QPD-MA $A 4 C+A 2 C$ & $45.6 \pm 21.5$ & 0.905 & $<0.0001$ & 1.7 & $-16.6 \sim 20.1$ & 0.0844 \\
\hline
\end{tabular}

QPD-MA $A_{P L A X}$ MRvol was measured by QPD using circular geometric assumption, and the MA diameter was measured in PLAX view, QPD-MA $A_{P L A X+A 4 C}$ MRvol was measured by QPD using ellipse assumption, and the MA diameter was measured in PLAX and A4C view, RT3DE MRvol was measured using EROA multiplied by the $\mathrm{VTI}_{\mathrm{MR}}$

$\mathrm{MA}_{\mathrm{A} 4 \mathrm{C}}$ were overestimated in $23(26.1 \%)$ patients and in $12(13.6 \%)$ patients, respectively, and MR severity using QPD-MA ${ }_{\mathrm{A} 2 \mathrm{C}}$ was underestimated in $7(10.2 \%)$ patients.

Based on that the MA is oval with the major and minor diameters previously demonstrated $[5,14,15]$. In this study, assuming that the MA was ellipse geometry, there was no significant difference of MRvol (mean difference $=1.7 \mathrm{ml}, P=0.0844)$ between the QPD-MA $44 \mathrm{C}+$ ${ }_{\mathrm{A} 2 \mathrm{C}}$ and the RT3DE. This is because the $\mathrm{MA}_{\mathrm{A} 4 \mathrm{C}}$ diameters may approach the $3 \mathrm{D}$ major diameters, and the $\mathrm{MA}_{\mathrm{A} 2 \mathrm{C}}$ may be close to the $3 \mathrm{D}$ minor diameters. The $\mathrm{CSA}_{\mathrm{MA}}$ calculated by $2 \mathrm{D} \mathrm{MA}_{\mathrm{A} 2 \mathrm{C}}$ and $\mathrm{MA}_{\mathrm{A} 4 \mathrm{C}}$ diameters using ellipse geometric assumption formula $\left(\mathrm{CSA}_{\mathrm{MA}}=\right.$ $0.785 \times \mathrm{a} \times \mathrm{b})$ may be closer to the real $\mathrm{CAS}_{\mathrm{MA}}$, which led to an accurate evaluation of corresponding $\mathrm{SV}_{\mathrm{MA}}$ and MRvol by QPD-MA $44 \mathrm{C}+\mathrm{A} 2 \mathrm{C}$ and may more accurately assess MR severity. In our present study, although MR severity using QPD-MA $\mathrm{A}_{4 \mathrm{C}}+\mathrm{A} 2 \mathrm{C}$ was slightly overestimated in $3(3.4 \%)$ patients, Chi-squared revealed no significant difference $(P=0.724)$. Since the MAPLAX diameter was larger than the $\mathrm{MA}_{\mathrm{A} 4 \mathrm{C}}(3.0 \pm 0.4$ vs $2.9 \pm$ $0.4, P<0.001$ ), which resulted in the fact that the $\mathrm{CSA}_{\mathrm{PLAX}}+\mathrm{A} 2 \mathrm{C}$ was larger than the $\mathrm{CSA}_{\mathrm{A} 4 \mathrm{C}+\mathrm{A} 2 \mathrm{C} \text {, the cor- }}$ responding MRvol by QPD-MAPLAX $+\mathrm{A} 2 \mathrm{C}$ was overestimated (mean difference $=6.8 \mathrm{ml}, P=0.0002$ ) compared with the RT3DE. As for the overestimation of MRvol (mean difference $=15.2 \mathrm{ml}, \quad P<0.0001$ ) by QPD$\mathrm{MA}_{\mathrm{PLAX}+\mathrm{A} 4 \mathrm{C}}$, this could be related to the fact that the $\mathrm{MA}_{\mathrm{A} 4 \mathrm{C}}$ diameter was larger than the $\mathrm{MA}_{\mathrm{A} 2 \mathrm{C}}(2.9 \pm 0.4$ vs $2.7 \pm 0.3, P<0.001$ ), which led to an overestimation of the corresponding CSA $\mathrm{PLAX}+\mathrm{A} 4 \mathrm{C}$ and $\mathrm{SV}_{\mathrm{MA}}$, thus overestimating the MRvol. The smaller difference of the result between the MRvol by QPD-MA $\mathrm{A}_{4 \mathrm{C}+\mathrm{A} 2 \mathrm{C}}$ and RT3DE was probably because the MA has an elliptic shape with a saddle-shaped 3D structure, and there are dynamic changes in its shape and position in different diseases during the cardiac cycle [17-20].
Previous study by Lewis JF observed a high correlation between thermodilution- derived stroke volume and Doppler-determined mitral inflow volume, and did not find significant difference between the use of assumption of a circular geometry of MA from the $\mathrm{A} 4 \mathrm{C}$ view and the use of assumption of an ellipse geometry of MA from the A4C and $\mathrm{A} 2 \mathrm{C}$ views [21]. However, the study by Rokey R found that the average regurgitant volume by the Doppler method $(6.04 \pm 3.091 / \mathrm{min})$, assuming that the MA was circular geometry from the $\mathrm{A} 4 \mathrm{C}$ view, was slightly higher than that obtained by angiography $(5.33 \pm 3.48 \mathrm{l} / \mathrm{min})$, although not significant [22]. Similar results were obtained in study by Enriquez-Sarano $\mathrm{M}$ in which the assumption of a circular geometry of MA from the $\mathrm{A} 4 \mathrm{C}$ view by the Doppler method mildly overestimated the MA stroke volume and significantly overestimated regurgitant volume [23]. Most of the earlier studies of Doppler method was mainly based on the standard angiographic grading method, which is subjective and influenced by many factors, including catheter position, rhythm disturbances, amount and velocity of dye injected, chamber size, and radiogram penetration [24]. Even the quantitative angiography, which makes use of left ventriculographic stroke volume for mitral valve flow and thermodilution for cardiac output, has conspicuous limitations. The error of cardiac output measurement is between 5 and $10 \%$ for thermodilution and between 10 and $15 \%$ for angiography, leading to a greater error when they are combined into the MR [24].

Echocardiography is the most commonly method for evaluating MR severity, and the QPD method has been successfully introduced into routine clinical practice for assessment of MR severity [4]. The QPD method is based on accurately evaluating the $\mathrm{CSA}_{\mathrm{MA}}$ and $\mathrm{CSA}_{\mathrm{L}}$ vот. The MA diameter was measured in the $\mathrm{A} 4 \mathrm{C}$ view and the $\mathrm{CSA}_{\mathrm{MA}}$ was derived as $0.785 \mathrm{~d}^{2}$ assuming that the MA is circular geometry as previously recommended [4]. Unfortunately, the human left heart and mitral valve 
do not provide the ideal conditions for the application of assumption of a circular geometry of MA, which eventually diminish the accuracy of assessment of MR severity. Previous studies have been demonstrated that the MA has a saddle-shaped contour and the CSA of the MA are oval $[5,13-15]$. Therefore, our aim of the present study is to find the appropriate geometric model and the optimal MA diameters combination for traditional 2D TTE through systematic research, so as to measure the MRvol by 2D TTE QPD more accurately. To the best of our knowledge, no clinical studies have assessed the impact different geometric assumption of MA on the assessment of MRvol by QPD. This study showed that the QPD-MA $\mathrm{A}_{4 \mathrm{C}}$ overestimated the MRvol assuming that the MA was circular geometry as previously recommended, and assuming that the MA is ellipse geometry, the MRvol with QPD-MA $\mathrm{M}_{4 \mathrm{C}+\mathrm{A} 2 \mathrm{C}}$ correlated well and had good agreement compared with MRvol using EROA by RT3DE multiplied by the VTI $\mathrm{MR}_{\text {. The }}$ QPD-MA $44 \mathrm{C}+$ A2C provided more accurate assessment of MRvol using ellipse assumption of MA than the QPD-MA $\mathrm{A}_{4 \mathrm{C}}$ applying circular assumption previously recommended.

\section{Limitations}

First, a limitation of a true gold standard for calculating MRvol was absent in the present study. In this study, the MRvol derived from EROA by RT3DE multiplied by the $\mathrm{VTI}_{\mathrm{MR}}$ was used as the reference method, which has been documented as an accurate method [6, 7], and some studies have used it as reference method [10, 25]. However, RT3DE has limited spatial resolution of the reconstructed image, which may lead to biased results [26]. Second, this study did not evaluate the dynamic changes of 3D structure and CSA of the MA in different diseases and cardiac cycles. Third, in this study, the relationship between 3D MA diameters and 2D diameters in different views, as well as the geometry of LVOT were not evaluated, which may add to further errors in calculating MRvol by QPD. Fourth, this present study did not address the significance to stratify the results in primary and secondary MR, and further researches and follow-up data are necessary to explore. Finally, further studies are needed to confirm the results of MRvol by QPD$\mathrm{MA}_{\mathrm{A} 4 \mathrm{C}+\mathrm{A} 2 \mathrm{C}}$ based on ellipse assumption of MA.

\section{Conclusion}

Assuming that the MA is circular geometry as previously recommended, the MRvol by $2 \mathrm{D}$ TTE QPD-MA $\mathrm{A}_{4 \mathrm{C}}$ was overestimated compared with the MRvol derived from EROA by RT3DE multiplied by the $\mathrm{VTI}_{\mathrm{MR}}$. However, assuming that the MA was ellipse geometry, the MRvol by the 2D TTE QPD-MA $\mathrm{A4C}+\mathrm{A} 2 \mathrm{C}$ was accurate compared with the reference method.

\section{Abbreviations}

2D: Two-dimensional; 3D: Three-dimensional; A2C: Apical two-chamber; A4C: Apical four-chamber; A5C: Apical five-chamber; CSA: Cross-sectional area; $\mathrm{CSA}_{\mathrm{A} 2}$ : The CSA of MA was calculated from the MA diameter in $\mathrm{A} 2 \mathrm{C}$ view using circular geometric assumption; $\mathrm{CSA}_{A 4 C}$ : The CSA of MA was calculated from the MA diameter in A4C view using circular geometric assumption; CSA LVOT: CSA of LVOT; CSAMA: CSA of MA; CSAPLAX + AZC: The CSA of MA was calculated from the MA diameter in PLAX and $A 2 C$ view using

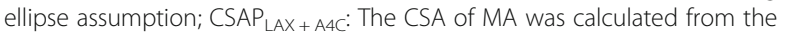
MA diameter in PLAX and A4C view using ellipse assumption; CSAPLAX: The CSA of MA was calculated from the MA diameter in PLAX view using circular geometric assumption; EROA: Effective regurgitant orifice area; LVOT: Left ventricular outflow tract; MA: Mitral annulus; $\mathrm{MA}_{\mathrm{Az}}$ : The diameter of MA was measured in the $\mathrm{A} 2 \mathrm{C}$ view; $\mathrm{MA}_{\mathrm{A} A C}$ : The diameter of MA was measured in the A4C view; MAPIAX: The diameter of MA was measured in the PLAX view; MR: Mitral regurgitation; MRvol: Mitral regurgitation volume; MV: Mitral valve; MVP: Mitral valve prolapse; PLAX: Parasternal long-axis; QPD: Quantitative pulsed Doppler; QPD-MA $A_{A 2 C}$ : MRvol was measured by QPD using circular geometric assumption, and the MA diameter was measured in $\mathrm{A} 2 \mathrm{C}$ view: QPD-MA $A_{A 4}$ : MRvol was measured by QPD using circular geometric assumption, and the MA diameter was measured in A4C view; QPD$M A_{A 4 C+A 2 C}$ : MRvol was measured by QPD using ellipse assumption, and the MA diameter was measured in A4C and A2C view; QPD-MAPLAX: MRvol was measured by QPD using circular geometric assumption, and the MA diameter was measured in PLAX view; QPD-MAPLAX+AzC: MRvol was measured by QPD using ellipse assumption, and the MA diameter was measured in PLAX and A2C view; QPD-MAPLAX+A4C: MRvol was measured by QPD using ellipse assumption, and the MA diameter was measured in PLAX and A4C view; RT3DE: Real time three-dimensional echocardiography; SV: Stroke volume; SV LVOT: LVOT forward stroke volume; SV MA: MA forward stroke volume; TTE: Transthoracic echocardiographic; VTI: Velocity-time integral; VTI LVOT: VTI of LVOT; VTI MA: VTI of MA; VTI MR: MR velocity-time integral

\section{Acknowledgements}

None.

Authors' contributions

WW and XF designed this study as the first author and corresponding author. ZW, JL, and KG were involved in image acquisition and analysis in this study. LZ and GT carried out the statistical analysis. All authors read and approved the final manuscript.

Funding

None.

\section{Availability of data and materials}

The data and materials used in this study are available from the corresponding author or the first author on reasonable request.

\section{Ethics approval and consent to participate}

This study was approved by the institutional review board of The Affiliated Hospital of Qingdao University, and all patients underwent echocardiographic examination because of clinical indications and gave written informed consent.

\section{Consent for publication}

The authors of this study agreed with this manuscript and its submission to Cardiovascular ultrasound.

\section{Competing interests}

The authors declare that they have no competing interests.

Received: 13 November 2019 Accepted: 27 January 2020

Published online: 31 January 2020

\section{References}

1. Enriquez-Sarano M, Avierinos JF, Messika-Zeitoun D, Detaint D, Capps M, Nkomo V, et al. Quantitative determinants of the outcome of asymptomatic mitral regurgitation. N Engl J Med. 2005;352:875-83. 
2. Zoghbi WA, Asch FM, Bruce C, Gillam LD, Grayburn PA, Hahn RT, et al. Guidelines for the evaluation of valvular regurgitation after percutaneous valve repair or replacement: a report from the American Society of Echocardiography developed in collaboration with the Society for Cardiovascular Angiography and Interventions, Japanese Society of Echocardiography, and Society for Cardiovascular Magnetic Resonance. J Am Soc Echocardiogr. 2019;32:431-75.

3. Nishimura RA, Otto CM, Bonow RO, Carabello BA, Erwin JP 3rd, Fleisher LA et al. 2017 AHA/ACC focused update of the 2014 AHA/ACC guideline for the management of patients with valvular heart disease. J Am Coll Cardiol. 2017;70:252-89.

4. Zoghbi WA, Adams D, Bonow RO, Enriquez-Sarano M, Foster E, Grayburn PA, et al. Recommendations for noninvasive evaluation of native valvular regurgitation: a report from the American Society of Echocardiography developed in collaboration with the Society for Cardiovascular Magnetic Resonance. J Am Soc Echocardiogr. 2017;30:303-71.

5. Ren B, de Groot-de Laat LE, McGhie J, Vletter WB, Ten Cate FJ, Geleijnse ML. Geometric errors of the pulsed-wave Doppler flow method in quantifying degenerative mitral valve regurgitation: a three dimensional echocardiography study. J Am Soc Echocardiogr. 2013;26:261-9.

6. Little SH, Pirat B, Kumar R, Igo SR, McCulloch M, Hartley CJ, et al. Three dimensional color Doppler echocardiography for direct measurement of vena contracta area in mitral regurgitation: in vitro validation and clinical experience. JACC Cardiovasc Imaging. 2008;1:695-704.

7. Marsan NA, Westenberg JJ, Ypenburg C, Delgado V, van Bommel RJ, Roes $S D$, et al. Quantification of functional mitral regurgitation by real time 3D echocardiography: comparison with 3D velocity-encoded cardiac magnetic resonance. JACC Cardiovasc Imaging. 2009;2:1245-52.

8. Shanks M, Siebelink HM, Delgado V, van de Veire NR, Ng AC, Sieders A. et, al. Quantitative assessment of mitral regurgitation: comparison between three-dimensional transesophageal echocardiography and magnetic resonance imaging. Circ Cardiovasc Imaging. 2010;3:694700 .

9. Quinones MA, Otto CM, Stoddard M, Waggoner A, Zoghbi WA, et al. Recommendations for quantification of Doppler echocardiography: a report from the Doppler quantification task force of the nomenclature and standards committee of the American Society of Echocardiography. J Am Soc Echocardiogr. 2002;15:167-84.

10. de Agustın JA, Marcos-Alberca P, Fernandez-Golfin C, Gonçalves A, Feltes G, Nuñez-Gil IJ, et al. Direct measurement of proximal isovelocity surface area by single-beat three-dimensional color Doppler echocardiography in mitral regurgitation: a validation study. J Am Soc Echocardiogr. 2012;25:815-23.

11. Thavendiranathan P, Phelan D, Collier P, Thomas JD, Flamm SD, Marwick TH. Quantitative assessment of mitral regurgitation: how best to do it. JACC Cardiovasc Imaging. 2012;5:1161-75.

12. Zoghbi WA, Enriquez-Sarano M, Foster E, Grayburn PA, Kraft CD, Levine RA et al. Recommendations for evaluation of the severity of native valvular regurgitation with two dimensional and Doppler echocardiography. J Am Soc Echocardiogr. 2003;16:777-802.

13. Levine RA, Handschumacher MD, Sanfilippo AJ, Hagege AA, Harrigan P, Marshall JE, et al. Three-dimensional echocardiographic reconstruction of the mitral valve, with implications for the diagnosis of mitral valve prolapse. Circulation. 1989:80:589-98.

14. Anwar AM, Soliman OI, Nemes A, Germans T, Krenning BJ, Geleijnse ML, et al. Assessment of mitral annulus size and function by real-time 3dimensional echocardiography in cardiomyopathy: comparison with magnetic resonance imaging. J Am Soc Echocardiogr. 2007;20:941-8.

15. Anwar AM, Soliman OI, ten Cate FJ, Nemes A, McGhie JS, Krenning BJ, et al. True mitral annulus diameter is underestimated by two-dimensional echocardiography as evidenced by real-time three-dimensional echocardiography and magnetic resonance imaging. Int J Cardiovasc Imaging. 2007;23:541-7.

16. Foster GP, Dunn AK, Abraham S, Ahmadi N, Sarraf G. Accurate measurement of mitral annular dimensions by echocardiography: importance of correctly aligned imaging planes and anatomic landmarks. J Am Soc Echocardiogr. $2009 \cdot 22 \cdot 458-63$

17. Kaplan SR, Bashein G, Sheehan FH, Legget ME, Munt B, Li XN, et al. Three-dimensional echocardiographic assessment of annular shape changes in the normal and regurgitant mitral valve. Am Heart J. 2000; 139:378-87.
18. Daimon M, Gillinov AM, Liddicoat JR, Saracino G, Fukuda S, Koyama Y, et al. Dynamic change in mitral annular area and motion during percutaneous mitral annuloplasty for ischemic mitral regurgitation: preliminary animal study with real-time 3-dimensional echocardiography. J Am Soc Echocardiogr. 2007;20:381-8.

19. Jolley MA, Ghelani SJ, Adar A, Harrild DM. Three-dimensional mitral valve morphology and age-related trends in children and young adults with structurally normal hearts using transthoracic echocardiography. J Am Soc Echocardiogr. 2017;30:561-71.

20. Chen TE, Ong K, Suri RM, Enriquez-Sarano M, Michelena HI, Burkhart HM, et al. Three-dimensional echocardiographic assessment of mitral annular physiology in patients with degenerative mitral valve regurgitation undergoing surgical repair: comparison between early- and late-stage severe mitral regurgitation. J Am Soc Echocardiogr. 2018;31:1178-89.

21. Lewis JF, Kuo LC, Nelson JG, Limacher MC, Quinones MA. Pulsed Doppler echocardiographic determination of stroke volume and cardiac output: clinical validation of two new methods using the apical window. Circulation. 1984;70:425-31

22. Rokey R, Sterling LL, Zoghbi WA, Sartori MP, Limacher MC, Kuo LC, et al. Determination of regurgitant fraction in isolated mitral or aortic regurgitation by pulsed Doppler two-dimensional echocardiography. J Am Coll Cardiol. 1986;7:1273-8.

23. Enriquez-Sarano M, Bailey KR, Seward JB, Tajik AJ, Krohn MJ, Mays JM. Quantitative Doppler assessment of valvular regurgitation. Circulation. 1993;87:841-8.

24. Chen CG, Thomas JD, Anconina J, Harrigan P, Mueller L, Picard MH, et al. Impact of impinging wall jet on color Doppler quantification of mitral regurgitation. Circulation. 1991;84:712-20.

25. Wang W, Lin $Q$, Wu W, Jiang $Y$, Lan T, Wang $H$. Quantification of mitral regurgitation by general imaging three-dimensional quantification: feasibility and accuracy. J Am Soc Echocardiogr. 2014;27:268-76.

26. Zeng X, Levine RA, Hua L, Morris EL, Kang Y, Flaherty M, et al. Diagnostic value of vena contracta area in the quantification of mitral regurgitation severity by color Doppler 3D-echocardiography. Circ Cardiovasc Imaging. 2011:4:506-13.

\section{Publisher's Note}

Springer Nature remains neutral with regard to jurisdictional claims in published maps and institutional affiliations.

\section{Ready to submit your research? Choose BMC and benefit from:}

- fast, convenient online submission

- thorough peer review by experienced researchers in your field

- rapid publication on acceptance

- support for research data, including large and complex data types

- gold Open Access which fosters wider collaboration and increased citations

- maximum visibility for your research: over $100 \mathrm{M}$ website views per year

At $\mathrm{BMC}$, research is always in progress.

Learn more biomedcentral.com/submissions 